\title{
Microstructure evolution in a new refractory high-entropy alloy
}

\section{W-Mo-Cr-Ti-Al}

\author{
B. Gorr ${ }^{\mathrm{a}}$, M. Azim ${ }^{\mathrm{a}}$, H.-J. Christ ${ }^{\mathrm{a}}$, H. Chen ${ }^{\mathrm{b}}$, D.-V. Szabo ${ }^{\mathrm{b}}$, A. Kauffmann ${ }^{\mathrm{b}}$, M. Heilmaier ${ }^{\mathrm{b}}$ \\ ${ }^{a}$ Institut für Werkstofftechnik, Universität Siegen, Paul-Bonatz-Str. 9-11, 57068 Siegen, Germany \\ ${ }^{b}$ Institut für Angewandte Materialien - Werkstoffkunde (IAM-WK), Karlsruhe Institute of Technology \\ (KIT), Engelbert-Arnold-Str. 4, D-76131 Karlsruhe, Germany \\ *Corresponding author: Email: gorr@ifwt.mb.uni-siegen.de; phone: +492717404653
}

\begin{abstract}
The microstructure of a body centered cubic 20W-20Mo-20Cr-20Ti-20Al alloy in the as-cast condition as well as its microstructural evolution during heat treatment was investigated. Different characterization techniques, such as focused ion beam - scanning electron microscope (FIB-SEM), X-ray diffraction (XRD), and transmission electron microscope TEM, were applied. Experimental observations were supported by thermodynamic calculations. The alloy exhibits a pronounced dendritic microstructure in the as-cast condition with the respective dendrite and interdendrite regions showing significant fluctuations of the element concentrations. Using thermodynamic calculations it was possible to rationalize the measured element distribution in the dendrite and the interdendrite regions. Observations of the microstructure evolution reveal that during heat treatment substantial homogenization takes place leading to the formation of a single phase microstructure. Driving forces for the microstructural evolution were discussed from a thermodynamic point of view.
\end{abstract}

\section{Introduction}

Metallic alloys with a beneficial combination of mechanical properties, easy formability, long-term stability, high temperature corrosion resistance, and low manufacturing costs have always been in great demand for industry $[1,2]$. Some of the recently developed high-entropy alloys (HEAs) have been proposed as possible candidates for applications in structural components operated at high temperatures due to their potentially perspective properties, such as excellent long-term phase stability and strength [3-7]. Along the lines of aiming at development of novel high temperature materials, a new equiatomic alloy system W-Mo-CrTi-Al has been proposed by Gorr et al. [8]. The alloy design concept supported by the thermodynamic analysis is generally based on the principle of HEAs. The microstructure and some properties of the first candidate from this new alloy family, namely the alloy W-Mo-Cr$\mathrm{Ti}-\mathrm{Al}$, were screened and presented in [8]. First microstructural investigations showed that the alloy in the as-cast condition exhibits a relatively inhomogeneous microstructure with pronounced dendritic and interdendritic regions. XRD results indicated that either two body centered cubic (bcc) phases with slightly different lattice parameters or one bcc phase with a lattice distortion form in the alloy in the as-cast condition. It was also found that the alloy possesses a high hardness of around $800 \mathrm{HV}$ and a relatively good oxidation resistance at 1273 $\mathrm{K}\left(1000^{\circ} \mathrm{C}\right)[8]$.

The identification of the phases present and investigation of their stability seems to be a general challenge in the exploration of the HEAs. For example, Cantor et al. [9] and later Otto 
et al. [10] reported that the equiatomic alloy $\mathrm{Fe}-\mathrm{Co}-\mathrm{Ni}-\mathrm{Cr}-\mathrm{Mn}$ consists of a single face centered cubic (fcc) solid solution phase. However, recent TEM investigations carried out by Liu et al. reveal that a second fcc phase might be present in this alloy [11]. The recent study by Schuh et al. also highlights the decomposition tendency of the alloy CoCrFeMnNi upon annealing after severe plastic deformation [12]. It was found that the hardness increase to a maximum of about $910 \mathrm{HV}$ after annealing at $723 \mathrm{~K}\left(450^{\circ} \mathrm{C}\right)$ can be attributed to the formation of three additional phases, a NiMn-rich, Cr-rich and FeCo-rich phase. Considering the fact that many HEAs containing additional phases often show beneficial properties compared to the truly single-phase materials, the HEA community discusses whether only single-phase materials should be classified as HEAs.

Since the combinations of compositions and processing routes of HEAs are numerous, each HEA usually possesses a unique microstructure and, consequently, different properties [1317]. Hence, thorough knowledge of microstructure in the equilibrium state, the microstructure evolution from the as-manufactured state towards equilibrium as well as understanding of the driving forces and relevant mechanisms causing the resulting microstructure are indispensible for alloy development and possible future industrial applications. Thus, in the present work, further detailed microstructural investigations of the alloy W-Mo-Cr-Ti-Al, which has been introduced in [8], were carried out for this alloy in the as-cast condition. Additionally, the microstructure evolution of the alloy during heat treatment processes was studied to gain a more comprehensive insight into the driving forces governing the formation of the alloy microstructure in the as-cast condition and during heat treatment.

\section{Experimental}

The alloy 20W-2Mo-20Cr-20Ti-20Al was produced from elemental bulk materials by arcmelting in $\sim 0.6 \mathrm{~atm}$ of argon utilizing an arc-melter AM 0.5 by Edmund Bühler $\mathrm{GmbH}$. The purities of the starting materials $\mathrm{Mo}, \mathrm{W}, \mathrm{Al}, \mathrm{Cr}$ and $\mathrm{Ti}$ were $99.9 \%, 99.96 \%, 99.9 \%, 99 \%$ and $99.8 \%$, respectively. Gaseous impurities such as oxygen and nitrogen were generally found to be on a very low level. While nitrogen was found to be below the detection limit, between 50 and 100 wt.ppm was measured for oxygen (see also [18]). The prepared buttons were flipped over and remelted more than five times in a water-chilled copper mold to facilitate alloy homogenization.

The alloy microstructure was analyzed by means of a FIB-SEM DualBeam system of type FEI Helios Nanolab 600. Utilizing this equipment, the TEM lamellae were prepared using a Ga ion beam. The crystal structure was identified by using the Panalytical X'Pert pro MPD Xray diffractometer applying $\mathrm{Cu} \mathrm{K} \alpha$ radiation. XRD in-situ measurements were conducted in an $\mathrm{Ar}$ atmosphere to avoid severe oxidation of the sample. TEM investigations were conducted in a FEI Tecnai 20F ST, operated at $200 \mathrm{kV}$. Bright-field images and electron diffraction images were acquired using a Gatan ORIUS CCD camera (2688 pixel x 2672 pixel). The camera length for electron diffraction $(150 \mathrm{~mm})$ was calibrated with an $\mathrm{Au}$ grating. Electron diffraction images were evaluated using the PASAD-Software tool [19] in Digital Micrograph ${ }^{\circledR}$ with respect to lattice parameters. Energy dispersive X-ray spectroscopy (EDS) spectra were acquired in scanning transmission electron microscope (STEM)-mode using a Si-Li detector with ultrathin window (EDAX, Mahwah, NJ, USA). 
To support experimental observation and to get fundamental knowledge of the alloy system, thermodynamic calculations were carried out using the software FactSage V6.4 in conjunction with a commercial database which includes elements constituting the alloy.

\section{Results}

\subsection{Alloy microstructure in the as-cast condition}

Figure 1(a) shows the microstructure of the alloy W-Mo-Cr-Ti-Al in the as-cast condition. The alloy exhibits a dendritic microstructure which is typical of many HEAs after casting [20]. The chemical compositions of dendritic and interdendritic regions were derived from EDS analyses conducted in the SEM (s. Fig. 1(b), (c)). The results of EDS analyses show that predominantly $\mathrm{W}$ and Mo are enriched in the dendrites, while the interdendritic regions are rich in $\mathrm{Al}, \mathrm{Cr}$, Ti. The data reveal, though, significant scatters of the element concentration values (see Figs. 1(b), (c)). This scatter is particularly pronounced for the element W within the dendrites. It is also noteworthy that even within the dendritic and interdendritic regions contrast differences are visible indicating substantial variations of the element concentrations within the corresponding regions (see e.g. the arrows pointing to local $\mathrm{W}$ enrichment in the dendrites in Fig. 1(a)).

Figure 1: (a) alloy microstructure (BSE mode) in the as-cast condition, (b) average values and scatter of the element concentration in the interdendrites, (c) average values and and scatters of the element concentration in the dendrites

It is likely to assume that the huge differences in the melting points of the alloy constituting elements cause the formation of the observed as-cast microstructure. The high melting elements $\mathrm{W}$ and Mo preferably solidify first as dendrites, while the lower melting elements $\mathrm{Cr}, \mathrm{Ti}$, and $\mathrm{Al}$ are enriched in the inderdendritic regions. In order to verify this assumption and to understand mechanisms leading (i) to the formation of the dendritic structure of the alloy W-Mo-Cr-Ti-Al in the as-cast condition and (ii) to the particular element distribution in respective areas, an iterative process of thermodynamic calculations was carried out. To simplify the iterative approach, calculation steps of $100 \mathrm{~K}\left(100^{\circ} \mathrm{C}\right)$ were chosen within a temperature range of $1973 \mathrm{~K}$ and $2673 \mathrm{~K}\left(1700^{\circ} \mathrm{C}\right.$ and $\left.2400^{\circ} \mathrm{C}\right)$, where only the liquid and a solid bcc phase can coexist according to previous thermodynamic calculations [8]. Each calculation starts out with the concentration of the liquid phase of the previous calculation which was performed for a temperature being $100 \mathrm{~K}\left(100^{\circ} \mathrm{C}\right)$ higher. The results of these calculations can be considered as a first approach of the alloy solidification process; they provide information on expected element concentration distribution between dendrite and interdendrite regions. It should be noted that the liquid phase, which is the only stable phase at $2673 \mathrm{~K}\left(2400^{\circ} \mathrm{C}\right)$, is equiatomic. At $2573 \mathrm{~K}\left(2300^{\circ} \mathrm{C}\right)$, the first step of the iterative thermodynamic calculations, element concentrations are obtained for the solid bcc phase which is formed from the equiatomic liquid phase. In the second step of the calculation, new element concentrations are calculated for the bcc phase that arises from the liquid phase with a new, i.e. non-equiatomic, composition that was in equilibrium with the bcc phase in the first step of calculation. In this way, the calculations proceeded towards lower temperatures. 
Exemplary results of this iterative process of thermodynamic calculations are shown in Fig. 2. It is evident that $\mathrm{W}$ plays the most important role in the bcc phase solidification at higher temperatures, however, its concentration decreases more rapidly compared to other elements. At lower temperatures, Al possesses the highest concentration in the bcc phase, but its fraction is significantly less pronounced compared to that of $\mathrm{W}$ at higher temperatures. In general, the left side of the diagram (at lower temperatures) can be considered being representative for the element distribution in the interdendrites, while the right side (higher temperatures) reflects the elemental distribution in the dendrites. Taking into account the calculation results presented in Fig.2, the scatter of the element concentrations shown in Fig. 1(b) and Fig. 1(c) can be rationalized as follows: the rapid decrease of the $\mathrm{W}$ concentration in the bcc phase at higher temperature (right side of Fig. 2) reflects the high scatter of the W concentration within the dendrites. In contrast, as the Mo concentration remains rather constant within a temperature interval ranging from $2073 \mathrm{~K}$ and $2573 \mathrm{~K}\left(1800^{\circ} \mathrm{C}\right.$ to $\left.2300^{\circ} \mathrm{C}\right)$, a rather small scatter of the Mo concentration within the dendrites results in Fig. 1 (c). However, at lower temperatures a notable decrease of the Mo concentration is observed (left side of Fig. 2) which readily explains the substantial scatter of Mo in the interdendrites (see Fig. 1(b)). The same method to analyze element concentration distribution between and within the dendrites and interdendrites can be applied for other elements.

Figure 2: element distribution in the bcc phase (results of iterative thermodynamic calculations using FactSage)

Earlier results of XRD measurements indicated that either two bcc phases with slightly different lattice parameters $(3.103 \AA$ and $3.116 \AA$ ) or one bcc phase with lattice distortion form in the alloy in the as-cast condition [5]. To get deeper insight into the microstructure of the alloy W-Mo-Cr-Ti-Al in the as-cast conditions, two TEM-lamellae were prepared using FIB technique targeted (i) at a dendrite and (ii) at an interdendritic region. Figure 3 represents results of the TEM investigations. In order to verify EDS data obtained in SEM (Fig. 1), additional EDS analyses were carried out in TEM. Figure 3 (b) shows exemplarily the spectrum of a spot marked in the dendrite TEM-lamella (Fig. 3(a)). The elements W, Mo, Ti, $\mathrm{Cr}$, and $\mathrm{Al}$ were detected. This is in agreement with EDS results from SEM measurements shown in Fig. 1(c). Furthermore, $\mathrm{Cu}$ stemming from the Cu-supporting TEM-grid, $\mathrm{Pt}$ stemming from the Pt protecting layer, and $\mathrm{Ga}$ stemming from the $\mathrm{Ga}$ ion source, were found. In contrary to many other HEAs, nano-particles were detected neither in the dendrite nor in the interdendrite regions. Selected area diffraction (SAD) patterns were used to determine the lattice parameter of the relevant areas and to compare these values with the earlier XRD analysis. The lattice parameter values were calculated from measured d values of (110), (200), (210), (211), (220), (310), and (321) reflections. For each region, 15 values were obtained from 5 different diffraction images. The averaged values of the lattice parameters are $3.154 \pm 0.002 \AA$ and $3.178 \pm 0.002 \AA$ for the interdendrite and the dendrite regions, respectively. Thus, in tendency the lattice parameter of the interdendrite region is slightly smaller than that of the dendrite region. However, the difference between two values is smaller than the accuracy of electron diffraction, since accuracy is usually in the region of $2-3 \%$ [21]. 
Interestingly, the lattice parameters determined by SAD are somewhat higher than those obtained from the XRD measurements. This difference can likely be attributed to the local concentration fluctuations within the respective dendrite and interdendrite regions which were observed in both, SEM and TEM (see Figs. 1 (b), (c) und Fig. 3(d)). Finally, Ga ions stemming from FIB preparation of the TEM lamellae may have an additional influence on the lattice parameter. Nevertheless, the tendency that the dendrite regions which contain more of the high melting and heavy elements possess a slightly larger lattice parameter is consistently confirmed by both measurement techniques.

Figure 3: TEM images of the alloy 20W-20Mo-20Cr-20Ti-20Al in the as-cast condition; (a) STEM image (overview) of the TEM lamella cut from a dendrite region, (b) EDS analysis of the spot marked in (a), (c) SAD pattern along [200] zone axis (sample tilt: $\alpha=-5,51^{\circ}, \beta=-$ $5,51^{\circ}$ ) within the dendrite, (d) calculated lattice parameters in the dendrite and the interdendrite regions

\subsection{Microstructural evolution during heat treatment}

As outlined in the introduction, it is of paramount interest to explore the microstructure stability at elevated temperatures. To study the microstructure evolution at moderately high temperature, in-situ XRD measurements were carried out. For this purpose, an as-cast alloy sample was heated stepwise in $200 \mathrm{~K}\left(200^{\circ} \mathrm{C}\right)$ steps from room temperature up to $1273 \mathrm{~K}$ $\left(1000^{\circ} \mathrm{C}\right)$. XRD measurements were conducted at each step with the temperature kept constant for $2 \mathrm{~h}$ at each step. The results show that two bcc phases could be identified at each temperature. The obtained values of the lattice parameters of both bcc phases at different temperatures are summarized in table 1 . In agreement with the TEM investigations shown above, it can be stated again that the dendrite phase possesses higher lattice parameters of $3.118 \AA$ and $3.148 \AA$, while the interdendrite phase has lower lattice parameters of $3.096 \AA$ and $3.138 \AA$ at room temperature and at $1000^{\circ} \mathrm{C}$, respectively. It is obvious that the difference between the lattice parameters of dendrites and interdendrites decreases continuously with increasing temperature underpinning the results of earlier measurements [8]. At $1273 \mathrm{~K}$ $\left(1000^{\circ} \mathrm{C}\right)$, this difference is negligibly small yielding a value of $0.010 \AA$ indicating the progressing homogenization process. This fact allows to state that the alloy $20 \mathrm{~W}-20 \mathrm{Mo}-20 \mathrm{Cr}-$ 20Ti-20Al possesses a single phase microstructure. It should finally be mentioned that during the in-situ XRD measurements small amounts of pure $\mathrm{W}$ and a Ti-Al compound were detected at $1273 \mathrm{~K}\left(1000^{\circ} \mathrm{C}\right)$. The formation of the last compound at $1273 \mathrm{~K}\left(1000^{\circ} \mathrm{C}\right)$ is, in fact, not surprising, as it was predicted by thermodynamic calculations [8]. The appearance of pure $\mathrm{W}$ will be discussed later in this section.

Table 1: lattice parameters of the two bcc phases obtained from in-situ XRD measurements (bcc1: dendrite, bcc2: interdendrite)

\begin{tabular}{|c|c|c|c|c|c|c|c|}
\hline $\begin{array}{c}\text { calculated lattice } \\
\text { parameter a }\end{array}$ & $\begin{array}{c}298 \mathrm{~K} \\
\left(25^{\circ} \mathrm{C}\right)\end{array}$ & $\begin{array}{c}473 \mathrm{~K} \\
\left(200^{\circ} \mathrm{C}\right)\end{array}$ & $\begin{array}{c}673 \mathrm{~K} \\
\left(400^{\circ} \mathrm{C}\right)\end{array}$ & $\begin{array}{c}873 \mathrm{~K} \\
\left(600^{\circ} \mathrm{C}\right)\end{array}$ & $\begin{array}{c}1073 \mathrm{~K} \\
\left(800^{\circ} \mathrm{C}\right)\end{array}$ & $\begin{array}{c}1273 \mathrm{~K} \\
\left(1000^{\circ} \mathrm{C}\right)\end{array}$ & $\begin{array}{c}\mathrm{a}_{1273 \mathrm{~K}}-\mathrm{a}_{298 \mathrm{~K}} \\
{[\AA]}\end{array}$ \\
\hline $\mathrm{a}(110) \mathrm{bcc} 1,[\AA]$ & 3.106 & 3.112 & 3.116 & 3.124 & 3.137 & 3.142 & \\
$\mathrm{a}(110) \mathrm{bcc} 2,[\AA]$ & 3.087 & 3.092 & 3.098 & 3.103 & 3.120 & 3.126 & \\
$\mathrm{a}(200) \mathrm{bcc} 1,[\AA]$ & 3.132 & 3.122 & 3.132 & 3.133 & 3.143 & 3.160 &
\end{tabular}




\begin{tabular}{|c|c|c|c|c|c|c|c|}
$\mathrm{a}(200) \mathrm{bcc} 2,[\AA]$ & 3.098 & 3.099 & 3.125 & 3.109 & 3.130 & 3.143 & \\
$\mathrm{a}(211) \mathrm{bcc} 1,[\AA]$ & 3.115 & 3.121 & 3.141 & 3.133 & 3.134 & 3.137 & \\
$\mathrm{a}(211) \mathrm{bcc} 2,[\AA]$ & 3.097 & 3.099 & 3.122 & 3.113 & 3.121 & 3.133 & \\
$\mathrm{a}(220) \mathrm{bcc} 1,[\AA]$ & 3.127 & 3.132 & 3.137 & 3.142 & 3.145 & 3.152 & \\
$\mathrm{a}(220) \mathrm{bcc} 2,[\AA]$ & 3.103 & 3.108 & 3.115 & 3.122 & 3.130 & 3.151 & \\
$\mathrm{a}(310) \mathrm{bcc} 1,[\AA]$ & 3.110 & 3.125 & 3.126 & 3.131 & 3.136 & - & \\
$\mathrm{a}(310) \mathrm{bcc} 2,[\AA]$ & 3.098 & 3.108 & 3.110 & 3.123 & 3.127 & - & \\
\hline $\mathrm{a}_{\mathrm{bcc1}},[\AA]$ & & & & & & & \\
$\mathrm{a}_{\mathrm{bcc} 2},[\AA]$ & 3.118 & 3.122 & 3.130 & 3.133 & 3.139 & 3.148 & 0.030 \\
\hline $\mathrm{a}_{\mathrm{bcc1}} \mathrm{a}_{\mathrm{bcc} 2},[\AA]$ & 0.022 & 0.021 & 0.016 & 0.019 & 0.013 & 0.010 & \\
\hline
\end{tabular}

Previous and current investigations reveal that the alloy 20W-20Mo-20Cr-20Ti-20Al shows a clear tendency to homogenize at high temperatures. After $40 \mathrm{~h}$ annealing at $1473 \mathrm{~K}\left(1200^{\circ} \mathrm{C}\right)$, a nearly fully homogeneous microstructure was observed in the alloy [8]. In order to examine the early stages of alloy homogenization as well as associated diffusion processes, heat treatments were carried out for 24 and $48 \mathrm{~h}$ at $1273 \mathrm{~K}\left(1000^{\circ} \mathrm{C}\right)$ and for $48 \mathrm{~h}$ at $1373 \mathrm{~K}$ $\left(1100^{\circ} \mathrm{C}\right)$. Figure 4 shows a decrease of the dendrite volume fraction in the alloy during heat treatment at $1000^{\circ} \mathrm{C}$. By means of the software tool Image $\mathrm{J}$, the changes of the dendrite volume fraction were quantified using the contrast differences between the interdendrite and the dendrite regions. The results are summarized in table 2. Obviously, the dendrite volume fraction decreases with increasing annealing time at $1273 \mathrm{~K}\left(1000^{\circ} \mathrm{C}\right)$ indicating that the complete homogenization would occur if the annealing temperature and the annealing time were chosen sufficiently high and long, respectively.

Figure 4: microstructure evolution of the alloy 20W-20Mo-20Cr-20Ti-20Al at $1273 \mathrm{~K}$ $\left(1000^{\circ} \mathrm{C}\right)$; (a) as-cast condition, (b) after $24 \mathrm{~h}$ at $1273 \mathrm{~K}\left(1000^{\circ} \mathrm{C}\right)$, and (c) after $48 \mathrm{~h}$ at $1273 \mathrm{~K}$ $\left(1000^{\circ} \mathrm{C}\right)$

Table 2: volume fraction of dendrite during heat treatment at $1273 \mathrm{~K}\left(1000^{\circ} \mathrm{C}\right)$

\begin{tabular}{|c|c|c|c|}
\hline annealing duration, [h] & 0 & 24 & 48 \\
\hline dendrite volume fraction, [\%] & 54 & 47 & 41 \\
\hline
\end{tabular}

Figure 5 shows the corresponding change of the element concentrations in the dendrite and interdendrite regions during heat treatment at $1273 \mathrm{~K}\left(1000^{\circ} \mathrm{C}\right)$. In the interdendrites, no significant changes were observed, while element concentrations in the dendrites change substantially: a moderate decrease of $\mathrm{Ti}$ and $\mathrm{Cr}$ and a notable decline of the Mo concentration were detected, while the Al concentration seems to remain nearly constant. A peculiar behavior is noted for tungsten in this region. Based on above findings, one would intuitively assume that the concentration of $\mathrm{W}$ would decrease in the dendrites and, consequently, increase in the interdendrites since the $\mathrm{W}$ content in the dendrites was found to be significantly higher than that in the interdendrites in the as-cast conditions (s. Fig. 1(b) und (c)). Instead, the tungsten content in the dendrites drastically increases, implying that $\mathrm{W}$ does not necessarily participate in the diffusion processes in the earlier stages of homogenization. Considering this very high $\mathrm{W}$ concentration in the dendrite as a result of the heat treatment, 
the lattice parameter of the dendrites obtained from the in-situ XRD measurements $(3.148 \AA$ ) at $1273 \mathrm{~K}\left(1000^{\circ} \mathrm{C}\right)$ can be reinterpreted in that the dendrite lattice constant should approach the value of pure tungsten. Karabacak et al. [22] determined the lattice parameter of pure $\mathrm{W}$ at $1223 \mathrm{~K}\left(950^{\circ} \mathrm{C}\right)$ yielding $3.157 \AA$ which is very close to the value of the dendrite lattice parameter obtained in our XRD measurements at $1273 \mathrm{~K}\left(1000^{\circ} \mathrm{C}\right)$. However, Fig. 6 clearly shows that the outward diffusion of $\mathrm{W}$ takes place in the sample that was heat-treated for $48 \mathrm{~h}$ at the higher temperature of $1373 \mathrm{~K}\left(1100^{\circ} \mathrm{C}\right)$, indicating that $\mathrm{W}$ leaves the dendrites when a critical value of the $\mathrm{W}$ concentration is exceeded or when the diffusivity of $\mathrm{W}$ becomes significant. It should be kept in mind that the diffusion of $\mathrm{W}$ becomes significant at high temperatures. Mundy et al. reported on the self diffusion coefficient in tungsten in the temperature range $1705 \mathrm{~K}-3408 \mathrm{~K}\left(1432-3135^{\circ} \mathrm{C}\right)$. At the lowest temperature, i.e. at $1705 \mathrm{~K}$ $\left(1432^{\circ} \mathrm{C}\right)$, the value of $\mathrm{D}=3.17 \times 10^{-18} \mathrm{~cm}^{2} / \mathrm{s}$ was obtained [23]. Considering the correlation between the element diffusivity and its melting temperature, it is obvious that the selfdiffusion of tungsten is substantially slower than the self-diffusion of the other alloy elements at $1273 \mathrm{~K}\left(1000^{\circ} \mathrm{C}\right)$.

Figure 5: element concentration changes in the interdendrite (a) and dendrite (b) regions at $1273 \mathrm{~K}\left(1000^{\circ} \mathrm{C}\right)$

Figure 6: element distribution in the alloy 20W-20Mo-20Cr-20Ti-20Al after 48 heat treatment at $1373 \mathrm{~K}\left(1100^{\circ} \mathrm{C}\right)$

\section{Discussion}

The experimental results presented in the previous section clearly show that the alloy $20 \mathrm{~W}$ 20Mo-20Cr-20Ti-20Al forms a dendritic microstructure with significant chemical differences between dendritic and interdendritic regions in the as-cast condition. It should be pointed out that the values of the elemental concentration attainable with EDS in SEM must be considered critically as relative errors up to \pm 8 percent can generally be expected [24]. However, these concentration values were confirmed by very similar concentration values measured in the ascasted alloy using TEM. Therefore, element concentrations obtained for the alloy after heat treatment using SEM can be used to identify mechanisms causing the microstructure evolution. In addition, to obtain the average values of element concentrations, for example in the dendrites, at least three dendrites were analyzed with at least three EDS measurements conducted in each of the dendrites. In other words, the average values and the connected scatter bars in Figs. 1 (b) and (c) represent at least 9 single measurements each. During heat treatment at high temperatures, the alloy tends to form a single bcc phase. To understand the mechanisms determining the microstructure evolution in the alloy, it is necessary to take a closer look at the driving forces governing the microstructural evolution.

In order to assess the kind of interaction prevailing between elements present in the alloy 20W-20Mo-20Cr-20Ti-20Al, enthalpies of mixing $\Delta H_{m i x}$ in the bcc phase for all binary and ternary equiatomic alloys were calculated using the software FactSage. The majority of the equiatomic systems show positive enthalpy of mixing. Only Al containing alloys apparently render negative enthalpy of mixing. Table 3 contains values for the four binary equiatomic systems containing $\mathrm{Al}$ at $1373 \mathrm{~K}\left(1100^{\circ} \mathrm{C}\right)$. As expected, the strongest bond energy should 
exist between $\mathrm{Al}$ and $\mathrm{Ti}$, followed by $\mathrm{Mo}, \mathrm{Cr}$, and $\mathrm{W}$. Based on these results, it can be supposed that Al strongly bonds primarily Ti building stable interdendrite regions. It should be noted that $\mathrm{Al}$ exhibits a notable attractive bond to Mo, too. This strong attractive interaction between $\mathrm{Al}$ and Mo may force Mo to leave dendrites to join Al predominantly enriched in inderdendrites. This assumption is consistent with the experimental observation that Mo concentration in the dendrites substantially decreases during heat treatment (s. Fig. $5(b))$.

Table 3: calculated enthalpy of mixing in binary systems at $1373 \mathrm{~K}\left(1100^{\circ} \mathrm{C}\right)$

\begin{tabular}{|l|c|c|c|c|}
\hline system & $\mathrm{Al}-\mathrm{Ti}$ & $\mathrm{Al}-\mathrm{Mo}$ & $\mathrm{Al}-\mathrm{Cr}$ & $\mathrm{Al}-\mathrm{W}$ \\
\hline$\Delta \mathrm{H}_{\mathrm{mix}}, \mathrm{kJ} / \mathrm{mol}$ & -30.8 & -18.9 & -13.9 & -6.9 \\
\hline
\end{tabular}

Further, $\Delta H_{m i x}$ was calculated for all bcc ternary systems at $1373 \mathrm{~K}\left(1100^{\circ} \mathrm{C}\right)$ in order to analyze the effect of the third element on the bond energy between two respective elements. The corresponding values are summarized in table 4. Again, only for Al containing systems negative values of enthalpy of mixing were calculated. Also, the bond energy between $\mathrm{Al}$ and Ti seems to be still dominant since the systems containing both elements show the lowest values of $\Delta H_{m i x}$. Interestingly, the ternary system Al-Ti-Mo yields the strongest bond energy among all ternary systems reinforcing the assumption that Mo in the dendrites is probably attracted by Al towards the interdendrites. In general, it can be concluded that Al shows a clear tendency to build up extremely strong bonds with other elements. In contrary, W effectively weakens the bonds between elements (compare, for example, enthalpy of mixing in Al-Ti-Mo and Al-W-Mo or in Al-Mo-Cr and Al-Cr-W).

Table 4: calculated enthalpy of mixing in ternary systems at $1373 \mathrm{~K}\left(1100^{\circ} \mathrm{C}\right)$

\begin{tabular}{|c|c|c|c|c|c|c|}
\hline system & Al-Ti-Mo & Al-Ti-Cr & Al-Ti-W & Al-Mo-Cr & Al-Mo-W & Al-Cr-W \\
\hline$\Delta \mathrm{H}_{\text {mix }}, \mathrm{kJ} / \mathrm{mol}$ & -21.3 & $-18,2$ & -16.8 & -11.2 & -11.1 & -5.7 \\
\hline
\end{tabular}

In order to understand the peculiar diffusion processes taking place during heat treatment as indicated in Fig. 5 and described in the previous section, activities of the elements in the alloy were calculated for the respective dendrite and the interdendrite regions at $1373 \mathrm{~K}\left(1100^{\circ} \mathrm{C}\right)$. The required chemical compositions for the dendrites and interdendrites were taken from Fig. 1 (b) and (c). The results are summarized in table 5. To understand the driving forces for diffusion of each element, the element activity differences $\Delta a_{i}$ between corresponding regions were calculated. For the sake of completeness, the element concentration differences $\Delta x_{i}$ were also determined. The results are shown in Fig. 7. Al and $\mathrm{W}$ are correlated with the highest values of $\Delta x_{i}$. This means that if diffusion of these elements takes place during heat treatment, the concentration changes are easily detectable. However, no significant concentration changes were detected for $\mathrm{Al}$, neither in the dendrites nor in the interdendrites. Taking the lowest value of the activity difference $\Delta a_{i}$ (s. Fig. 7) into account, it becomes clear that despite the fact that the concentration difference $\Delta x_{i}$ is very high, Al possesses the lowest driving force for diffusion in the alloy studied. Further, $\mathrm{Ti}$ and $\mathrm{Cr}$ exhibit significantly higher activity values in the dendrites than in the interdendritic regions creating a driving force for outward diffusion of these elements from dendrites into interdendrites as actually observed during heat 
treatment (s. Fig. 5(b)). Finally, considering the results shown in Fig. 7 it can be explained why the Mo concentration in the dendrites decreases, while the $\mathrm{W}$ content notably increases during heat treatment despite the higher $\Delta x_{i}$ of $\mathrm{W}$ than that of Mo (s. Fig. 5(b)). Apparently, this can be attributed to the fact that the activity difference $\Delta a_{i}$ of Mo is substantially higher compared to that of $\mathrm{W}$. The outward diffusion of Mo from the dendrites is, therefore, preferential from a thermodynamic point of view.

Table 5: calculated element activities for the dendrite and interdendrite regions

\begin{tabular}{|c|c|c|c|c|c|}
\hline Element & $\mathrm{Al}$ & $\mathrm{Ti}$ & $\mathrm{Cr}$ & Mo & W \\
\hline $\mathrm{a}^{\text {interdendrite }}$ & 0.031 & 0.11 & 0.357 & 0.127 & 0.59 \\
\hline $\mathrm{a}^{\text {dendrite }}$ & 0.005 & 0.22 & 0.51 & 0.22 & 0.64 \\
\hline
\end{tabular}

Figure 7: calculated concentration and activity differences of elements between dendrite and interdendrite regions

The results shown in Fig. 7 raise further questions such as why the activity difference of $\mathrm{W}$ between dendrite and interdendrite regions was found unexpectedly small? Or, in other words, how does each element influence the activity and, therefore, affect the driving force of concentration changes by diffusion of other elements in the alloy studied? Figure 8 shows results of thermodynamic calculations illustrating the effect of the element concentration on the activity of other elements constituting the alloy 20W-20Mo-20Cr-20Ti-20Al. Activities of four elements were calculated as a function of the concentration of the fifth element at $1273 \mathrm{~K}$ $\left(1000^{\circ} \mathrm{C}\right)$, assuming that the bcc phase is the only stable phase at this temperature. The concentrations of other elements were kept equal. It is obvious that both, $\mathrm{Cr}$ and $\mathrm{W}$, have no significant effect on the activities of the other elements (s. Fig. 8 (a) and (b)). Ti exhibits the same negligibly small impact (not shown here). Mo, in contrary, significantly diminishes the W activity (s. Fig. 8(c)). This implies that a high Mo content in the dendrites decreases the W activity in this region. In addition, the low content of $\mathrm{Al}$ in the dendrites decreases the $\mathrm{W}$ activity even further. The opposite effect occurs for $\mathrm{W}$ in the interdendrites: the low Mo and high $\mathrm{Al}$ concentrations cause an enhancement of the $\mathrm{W}$ activity. As a result, a low $\mathrm{W}$ activity difference results between the dendrite and interdendrite regions (s. Fig. 7). Interestingly, Al considerably influences the activities of all elements in the alloy. The $\mathrm{Cr}$ activity, for example, substantially decreases with increasing $\mathrm{Al}$ content. As a consequence, the low $\mathrm{Al}$ content in the dendrites results in a $\mathrm{Cr}$ activity being higher in the dendrite than in the interdendrite (s. table 5). In turn, this leads to the outward diffusion of $\mathrm{Cr}$ from the dendritic into the interdendritic regions (s. Fig. 5(b)). The same observation holds true for Ti.

Figure 8: effect of element concentrations on the element activity

\section{Conclusions}

The following main results were obtained in this study: 
- The microstructure of the alloy 20W-20Mo-20Cr-20Ti-20Al in the as-cast condition was investigated using various experimental techniques such as SEM, TEM, XRD. It was found that primarily $\mathrm{W}$ and Mo are enriched in the dendrites, while interdendrites are rich in $\mathrm{Al}, \mathrm{Cr}$, Ti. Within both regions, elemental distribution is not homogeneous as significant scatter of elemental concentrations was measured. W exhibits a particularly large concentration scatter from 26 at.\% to 49 at.\% in the dendrites. This feature was explained by an iterative of thermodynamic calculation procedure reflecting the element distribution in both relevant regions. Lattice parameter for the dendrite and interdendrite areas were determined as $3.178 \AA$ and $3.154 \AA$, respectively, using TEM. These values confirm the trend observed earlier by XRD.

- The homogenization process of the alloy 20W-20Mo-20Cr-20Ti-20Al was investigated by monitoring the microstructure evolution during and short-term annealings at moderate temperature $\left(473 \mathrm{~K}-1273 \mathrm{~K}\left(200^{\circ} \mathrm{C}-1000^{\circ} \mathrm{C}\right)\right)$ as well as longterm treatments at elevated temperatures $\left(1273 \mathrm{~K}-1373 \mathrm{~K}\left(1000^{\circ} \mathrm{C}-1100^{\circ} \mathrm{C}\right)\right)$. It was observed that the difference in the lattice parameters becomes less pronounced with increasing annealing temperature and time $\left(0.022 \AA\right.$ at $289 \mathrm{~K}\left(25^{\circ} \mathrm{C}\right)$ and $0.010 \AA$ at $\left.1273\left(1000^{\circ} \mathrm{C}\right)\right)$. The alloy shows, therefore, a clear tendency to homogenize and possesses a single phase microstructure. A significant decrease of the dendrite volume fraction from $53,9 \mathrm{vol} . \%$ to 41,1 vol. $\%$ was detected during annealing for up to $48 \mathrm{~h}$ at $1273 \mathrm{~K}\left(1000^{\circ} \mathrm{C}\right)$.

- Thermodynamic calculations were conducted to assess the driving forces governing the alloy microstructure evolution. The calculations of the enthalpy of mixing for binary and ternary systems reveal that Al builds the strongest bonds with other elements, especially with Ti. In contrast, W seems to weaken the bonds between elements. The activity differences between dendrites and interdendrites for corresponding elements were calculated. It was found that the experimentally observed microstructure evolution during heat treatment is in good agreement with these parameter values. The knowledge of the effect of element concentration on the element activity is important to understand the driving forces determining the alloy constitution.

Acknowledgment The financial support by the Deutsche Forschungsgemeinschaft (DFG) is gratefully acknowledged.

\section{References}

[1] Perepezko, J.H.: The hotter the engine, the better, Science, 326 (2009) 1068.

[2] Zhao, J-C., Westbrook, J.H.: Ultrahigh-temperature materials for jet engines, Material Research Society, 28 (2003) 622.

[3] Senkov, O.N., Scott, J.M., Senkova, S.V., Miracle, D.B., Woodward, C.F.: Microstructure and room temperature properties of a high-entropy TaNbHfZrTi alloy, Journal of Alloys and Compounds, 509 (2011) 6043.

[4] Tang, Z., Gao, M.C., Diao, H., Yang, T., Liu, J., Zuo, T., Zhang,Y., Lu, Z., Chen, Y., Zhang, Y., Dahmen, K.A., Liaw, P.K., Egami, T.: Aluminium alloying effects on 
lattice types, microstructures, and mechanical behavior of high-entropy alloys systems, JOM, 65 (2013) 1848.

[5] Zou, Y., Maiti, S., Steurer, W., Spolenak, R.: Size-dependent plasticity in an $\mathrm{Nb}_{25} \mathrm{Mo}_{25}$ $\mathrm{Ta}_{25} \mathrm{~W}_{25}$ refractory high-entropy alloy, Acta Materialia, 65 (2014) 85.

[6] Huhn, W.P., Widom, M.: Prediction of A2 to B2 phase transition in the high-entropy alloy Mo-Nb-Ta-W, JOM, 65 (2013) 1772.

[7] Yeh, J.W.: Alloy design strategies and future trends in high-entropy alloys, JOM, 65 (2013) 1759.

[8] Gorr, B, Azim M., Christ H.-J., Mueller T., Schliephake D., Heilmaier, M.: Phase equilibria, microstructure, and high temperature oxidation resistance of novel refractory high-entropy alloys, Journal of Alloys and Compounds, 624 (2015) 270.

[9] Cantor B., Chang, I.T.H., Knight P., Vincent, A.J.B.: Microstructural development in equiatomic multicomponent alloys, Material Science and Engineering A, 375-377 (2004) 213-218.

[10] Otto, F., Yang, Y., Bei, H., George, E.P., : Relative effects of enthalpy and entropy on the phase stability of equiatomic high-entropy alloys, Acta Materialia, 61 (2013) 2628

[11] Liu, W.H., Wu, Y., He, J.Y., Zhang, Y., Kuz, C.T., Lu, Z.P.: The phase competition and stability of high-entropy alloys, JOM, 66 (2014) 1973.

[12] Shuh, B., Mendez-Martin, F., Volker, B., George, E.P., Clemens, H., Pippan, R., Hohenwarter, A.: Mechanical porperties, microstructure and thermal stability of a nanocrystalline $\mathrm{CoCrFeMnNi} \mathrm{high-entropy} \mathrm{alloy} \mathrm{after} \mathrm{severe} \mathrm{plastic} \mathrm{deformation,} \mathrm{Acta}$ Materialia, 96 (2015) 258.

[13] Chen, M.R., Lin, S.J, Yeh, J.W., Chen, S.K., Huang, Y.S., Tu, C.P.: Microstructure and properties of $\mathrm{Al}_{0.5} \mathrm{CoCrCuFeNiTi}_{\mathrm{x}}(\mathrm{x}=0-2.0)$ high-entropy alloys, Materials Transactions, 47 (2006) 1395.

[14] Zhou, Y.J., Zhang, Y., Wang, Y.L., Chen, G.L.: Microstructure and compressive properties of multicomponent $\mathrm{Al}_{\mathrm{x}}(\mathrm{TiVCrMnFeCoNiCu})_{100-\mathrm{x}}$ high-entropy alloys, Materials Science and Engineering A, 454-455 (2007) 260.

[15] Guo, S., Liu, C.T.: Phase stability in high entropy alloys: Formation of solid-solution phase or amorphous phase, Progress in Natural Science: Materials International, 21 (2011) 433.

[16] Otto, F., Dlouhy, A., Somsen, Ch., Bei, H., Eggeler, G., George, E.P.: The influence of temperature and microstructure on the tensile properties of a $\mathrm{CoCrFeMnNi}$ highentropy alloy, Acta Materialia, 61 (2013) 5743.

[17] Senkov, O.N., Woodward, C., Miracle, D.B.: Microstructure and properties of aluminium-containing refractory high-entropy alloys, JOM, 66 (2014) 2030. 
[18] Chen, H., Kauffmann, A., Gorr, B., Schliephake, D., Seemüller, C., Wagner, J.N., Christ, H-J., Heilmaier, M.: Microstructure and mechanical properties at elevated temperatures of a new Al-containing refractory high-entropy alloy $\mathrm{Nb}-\mathrm{Mo}-\mathrm{Cr}-\mathrm{Ti}-\mathrm{Al}$, submitted to Journal of Alloys and Compounds.

[19] Gammer, C., Mangler, C., Rentenberger, C., Karnthaler, H.P.: Quantitative local profile analysis of nanomaterials by electron diffraction, Scripta Materialia 63 (2010) 312.

[20] Yeh, J.W., Chen, S.K., Lin, S.J., Gan, J.Y., Chin, T.S., Shun, T.T., Tsau, C.H., Chang, S.Y.: Nanostructured high-entropy alloys with multiple principle elements, novel alloy design, concept and outcomes, Advanced Engineering Materials, 6 (2004) 299.

[21] Williams, D.B., Carter, C.B.: Transmission Electron Microscopy: a Textbook for Materials Science, (1996) Plenum Press New York.

[22] Karabacak, T, Wang, P.I., Wang, G.C., Lu, T.M.: Phase transformation of single crystal $\beta$-tungsten nanorods at elevated temperatures, Thin Solid Films, 493 (2005) 293.

[23] Mundy, J.N., Rothman, S.J., Lam, N.Q., Hoff, H.A., Nowiski, L.J.: Self diffusion in tungsten, Physical Review B, 18 (1978) 6566.

[24] Miler, M., Mirtic, B.: Accuracy and precision of EDS analysis for identification of metal-bearing minerals in polished and rough particles samples, Geologija, 56/1 (2013) 5 . 


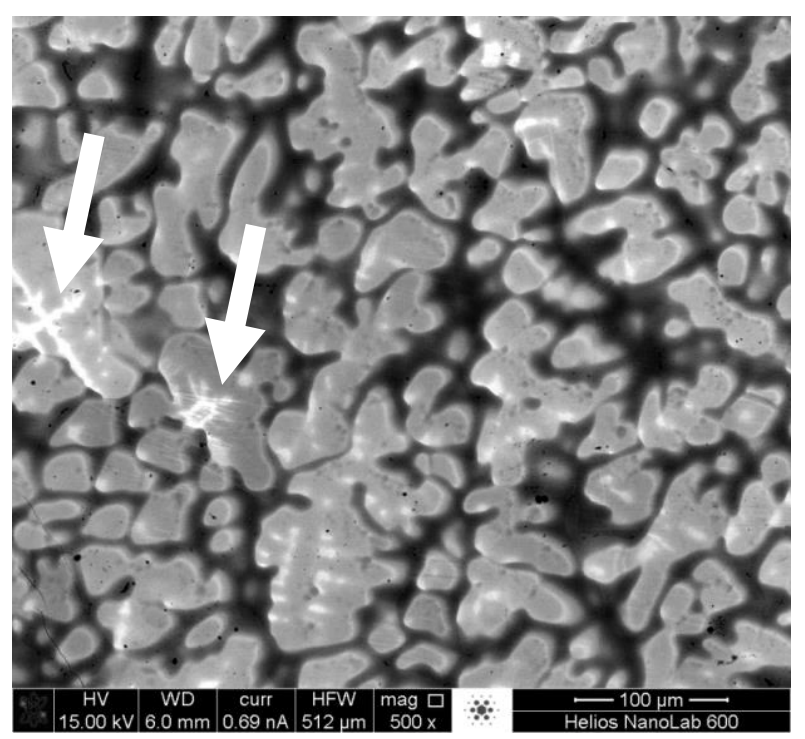

(a)

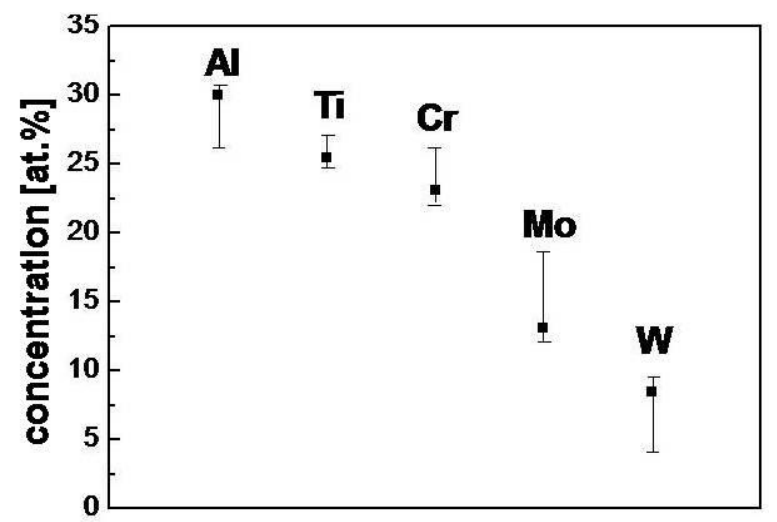

(b)

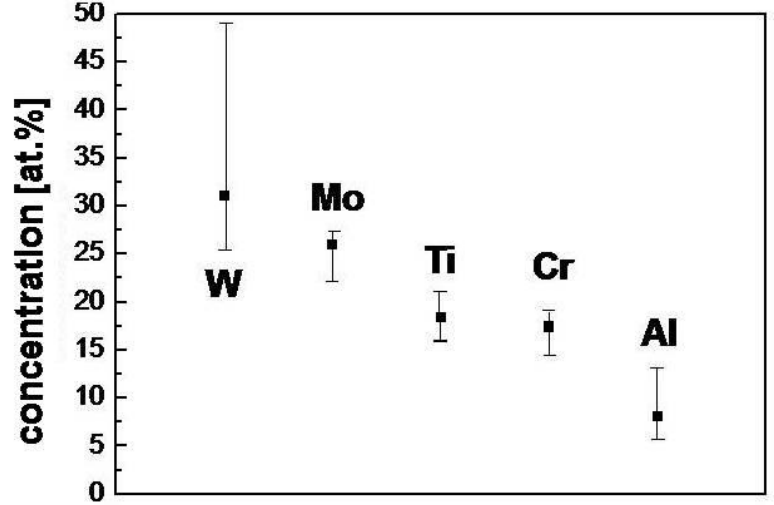

(c)

Figure 1: (a) alloy microstructure (BSE mode) in the as-cast condition, (b) average values and scatter of the element concentration in the interdendrites, (c) average values and scatters of the element concentration in the dendrites

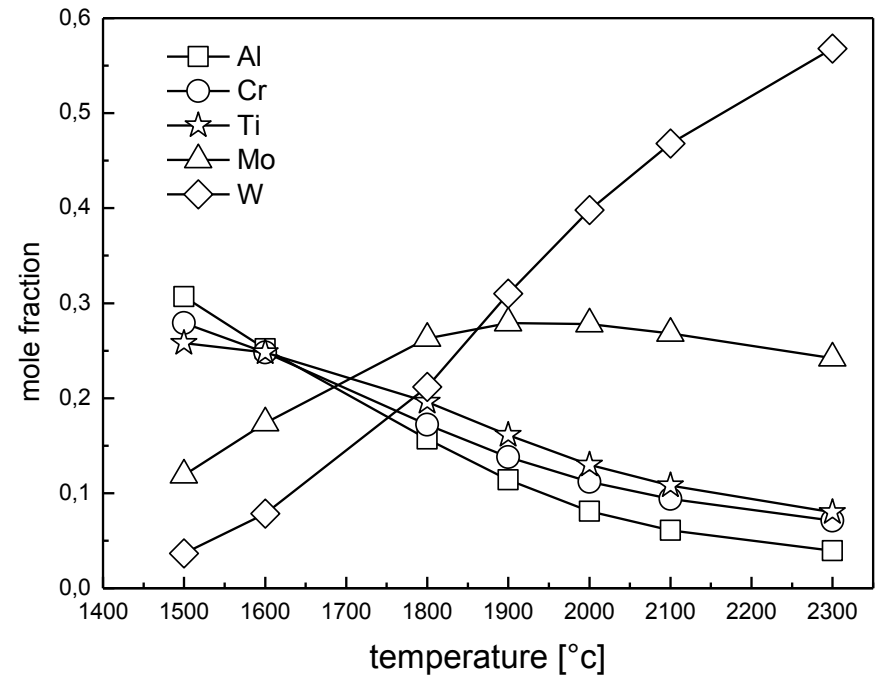


Figure 2: element distribution in the bcc phase (results of iterative thermodynamic calculations using FactSage)

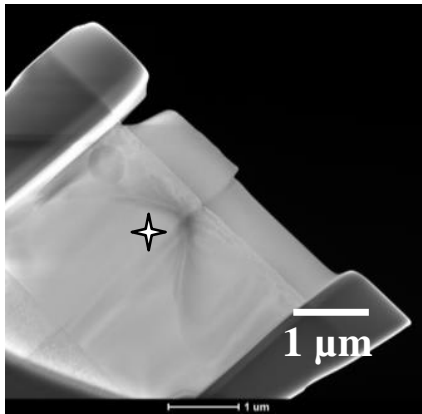

(a)

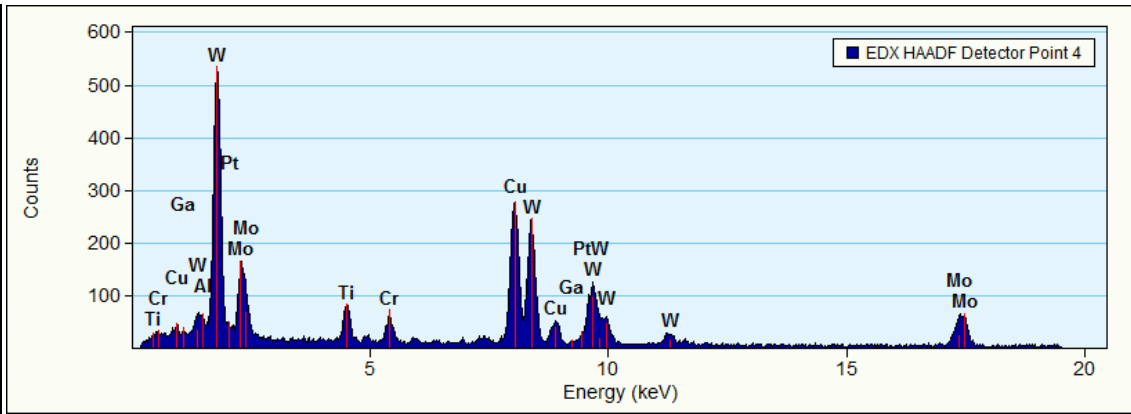

(b)

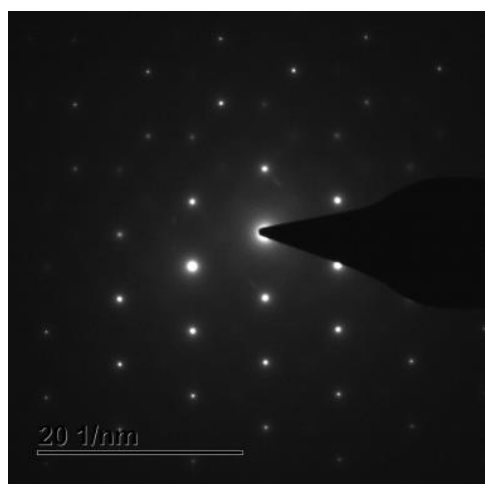

(c)

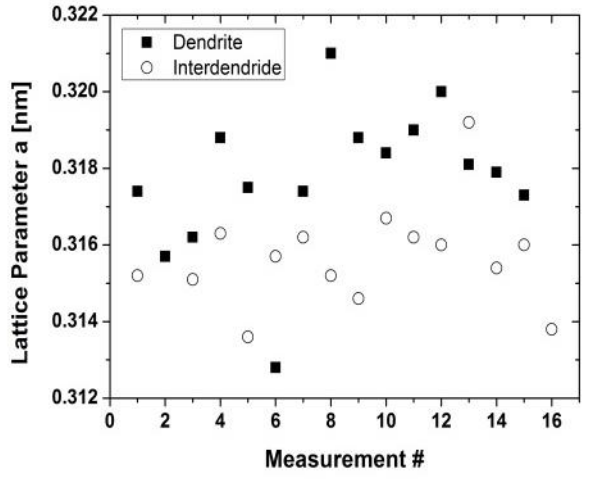

(d)

Figure 3: TEM images of the alloy 20Mo-20W-20Al-20Cr-20Ti in the as-cast condition; (a) STEM image (overview) of the TEM lamella cut from a dendrite region, (b) EDS analysis of the spot marked in (a), (c) SAD pattern along [200] zone axis (sample tilt: $\alpha=-5,51^{\circ}, \beta=-$ $5,51^{\circ}$ ) within the dendrite, (d) calculated lattice parameters in the dendrite and the interdendrite regions

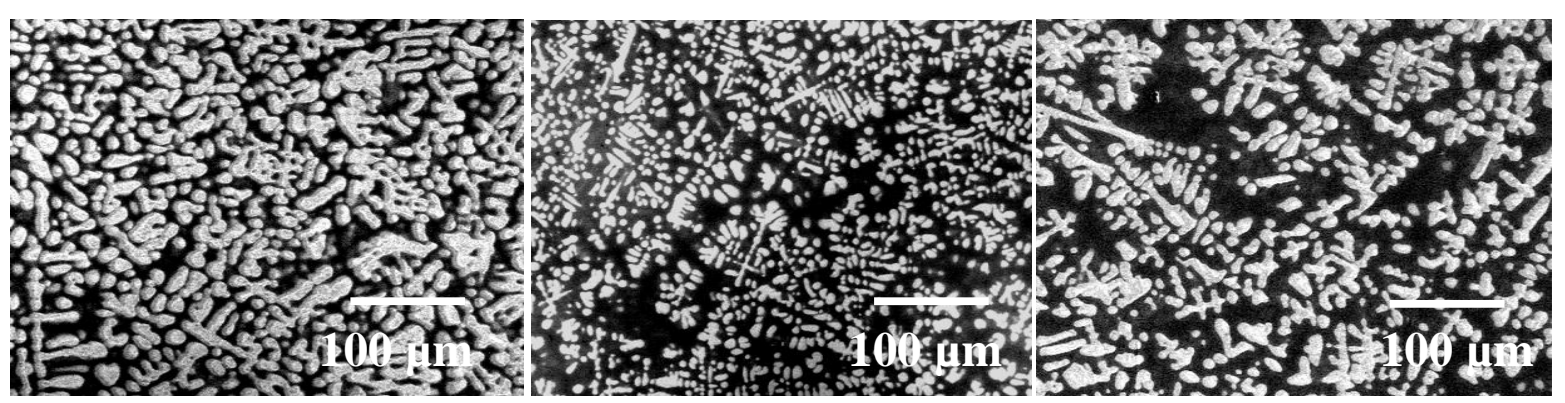

Figure 4: microstructure evolution of the alloy 20Mo-20W-20Al-20Cr-20Ti at 1273 $\left(1000^{\circ} \mathrm{C}\right)$; (a) as-cast condition, (b) after $24 \mathrm{~h}$ at $1273 \mathrm{~K}\left(1000^{\circ} \mathrm{C}\right)$, and (c) after $48 \mathrm{~h}$ at $1273 \mathrm{~K}$ $\left(1000^{\circ} \mathrm{C}\right)$ 


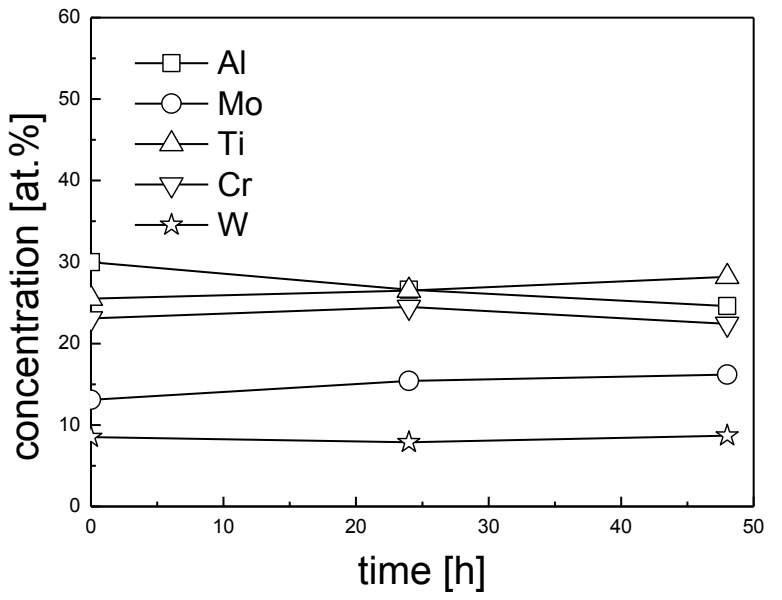

(a)

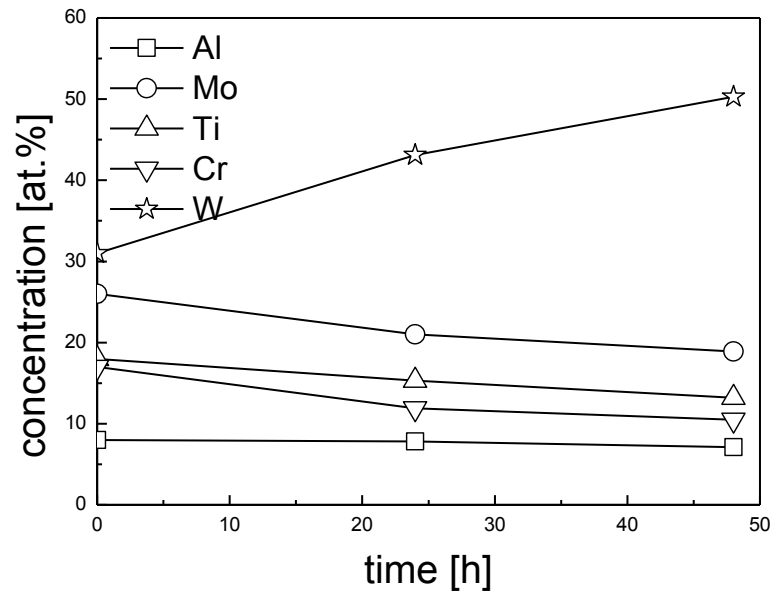

(b)

Figure 5: element concentration changes in the interdendrite (a) and dendrite (b) regions at $1273 \mathrm{~K}\left(1000^{\circ} \mathrm{C}\right)$
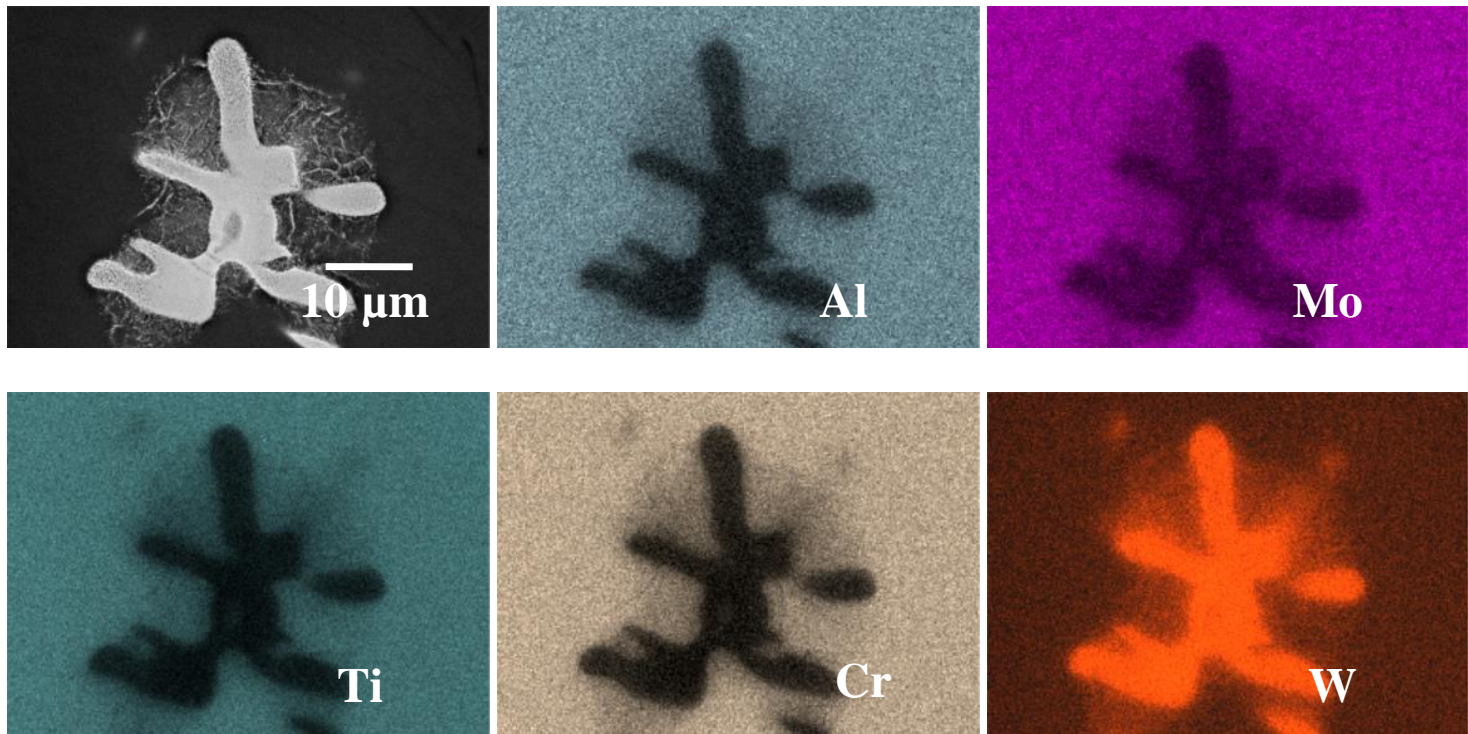

Figure 6: element distribution in the alloy 20Mo-20W-20Al-20Cr-20Ti after 48 heat treatment at $1373 \mathrm{~K}\left(1100^{\circ} \mathrm{C}\right)$ 


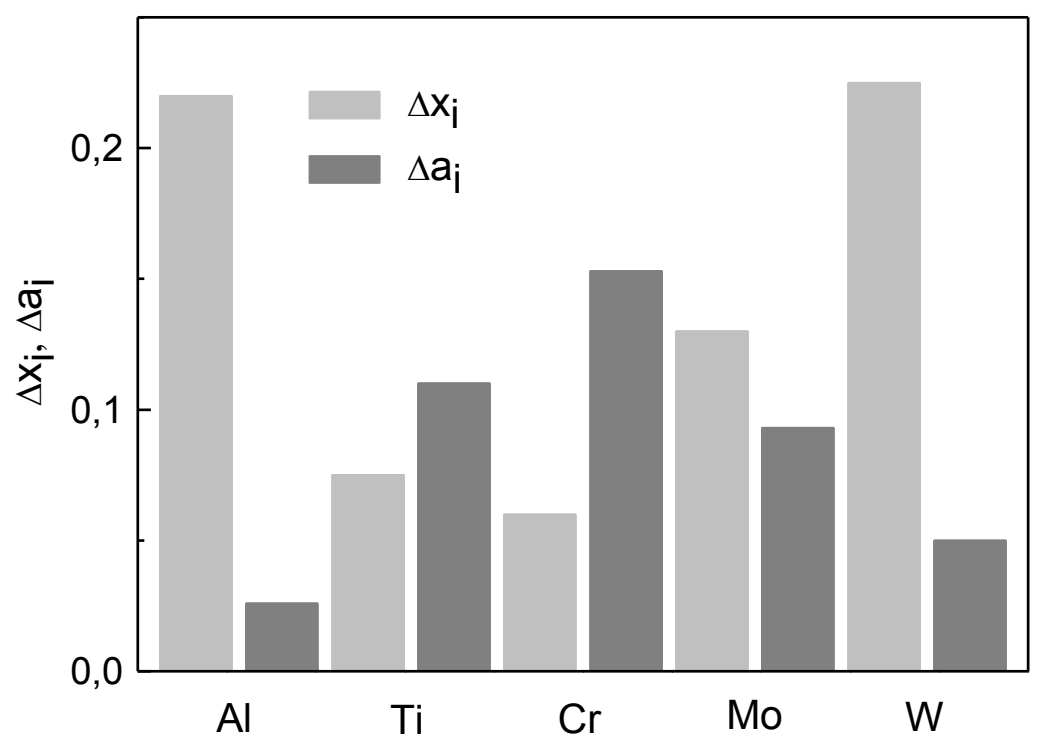

Figure 7: calculated concentration and activity differences of elements between dendrite and interdendrite regions

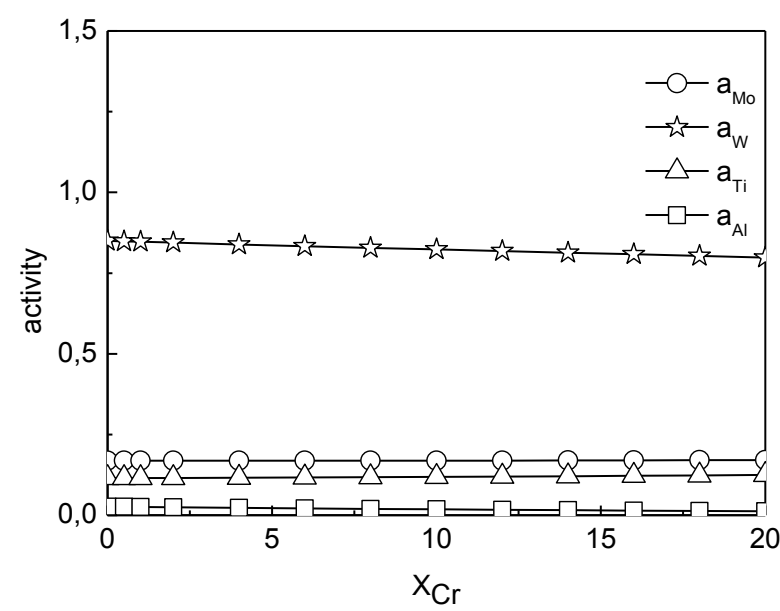

(a)

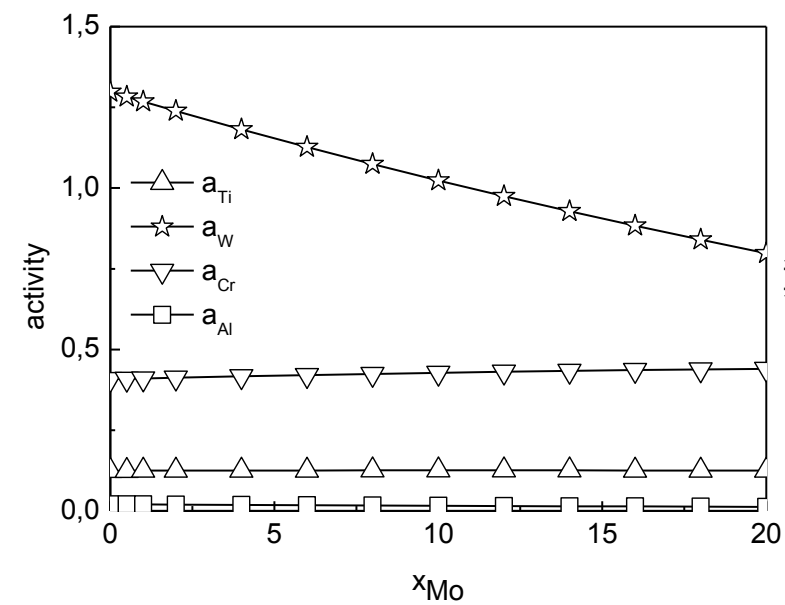

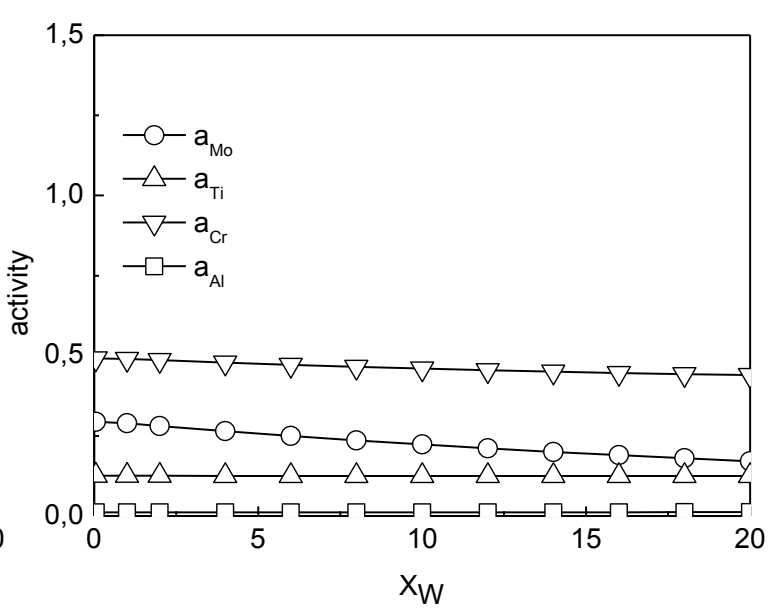

(b)

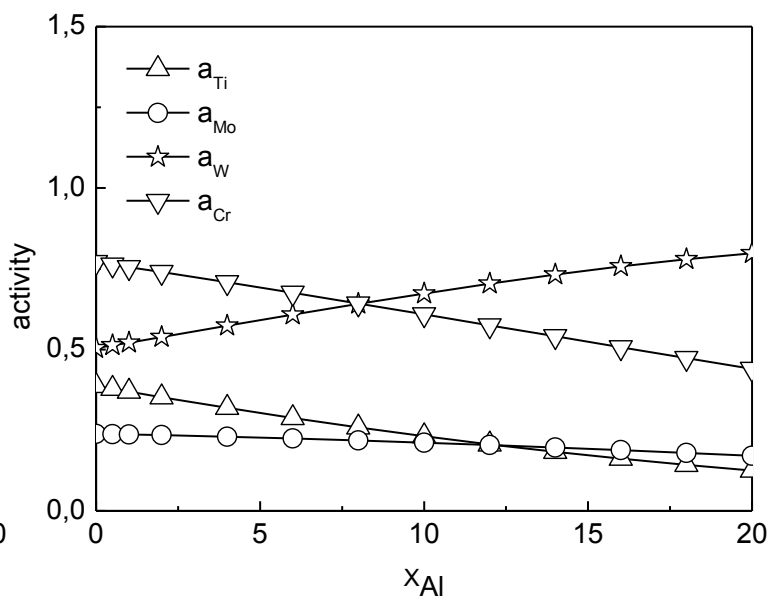


(c)

(d)

Figure 8: effect of element concentrations on the element activity 